\title{
MUSINGS
}

\section{Public perception of stem cell and genomics research}

\author{
M William Lensch",2,3*
}

\section{The importance of stem cells and genomics for translational research}

The confluence of human stem cell and genome research is laden with opportunity. Information gleaned from the Human Genome Project (HGP) has already done much to expand our understanding of human biology and disease (reviewed in [1]). The same can be said of human pluripotent stem cell (hPSC) research involving human embryonic stem cells (hESCs) and induced pluripotent stem cells (iPSCs). For translational stem cell research, especially where it involves reprogramming of mature cells to make iPSCs and their subsequent directed differentiation to other clinically useful cells and tissues, obtaining a deeper understanding of the role of genomewide transcriptional and epigenetic alterations will be invaluable. Taking the stem cells and genomics relationship to the next level seems like a good idea.

The availability of hPSCs has accelerated research into the underpinnings of development and genetic disease. Such cells provide abundant starting material for a range of in vitro studies, for example: (i) tissues representing hard-to-access anatomical locations; (ii) a wide variety of genetic backgrounds; (iii) disease models, using iPSCs derived from patients for whom the investigator has access to a detailed clinical history; and (iv) the opportunity to monitor tissue genesis at its earliest stages in health and disease alike (reviewed in [2]). The current frequency of papers describing novel hPSC-based model systems of human diseases reminds me of the heyday of gene mapping/identification studies in the late 1980s and early 1990s. Back then, it was commonplace to pick up the latest issue of nearly any leading journal and find papers describing disease-causing genes. It felt like a human genetics renaissance.

\footnotetext{
*Correspondence: Mathew.Lensch@childrens.harvard.edu 'Department of Pediatrics, Harvard Medical School, 300 Longwood Avenue, Boston, MA 02115, USA

${ }^{2}$ Harvard Stem Cell Institute, Holyoke Center, 1350 Massachusetts Avenue, Cambridge, MA 02138, USA

${ }^{3}$ Division of Hematology/Oncology, Children's Hospital Boston, 1 Blackfan Circle, Boston, MA 02115, USA
}

Today, hPSCs are facilitating new types of hypothesisdriven research in human genetics, including studies of complex, multifactorial conditions. When combined with powerful and ever-cheaper DNA sequencing technology [3] nothing short of a second renaissance in human genetics research becomes possible. As but one example, iPSCs can be used to generate banks of representative genotypes in certain diseases. The scalability of cultured iPSCs, potential for genetic modification and capacity to differentiate into disease-affected tissues permits extensive studies of genotype-phenotype relationships, the identification of disease-modifying loci and more (reviewed in [2]).

\section{The public perception of translational stem cell and genomics research}

The concert of stem cell and genomics research has great potential; however, it risks amplifying the sour notes of each when it comes to public need, expectation and vulnerability. The emergence of fraudulent 'stem cell clinics' worldwide [4] led the International Society for Stem Cell Research (ISSCR) to make recommendations regarding the conduct of translational stem cell research [5]. The potential for harm from unproven cellular therapies further pushed the ISSCR to establish a website providing advice to consumers [6]. Using this website, individuals may go so far as to request a review of information provided by a 'clinic' offering stem-cell-based treatments.

On the side of genomics, the US Food and Drug Administration has become quite interested in direct-toconsumer marketing of genetic tests [7]. A recent commentary by J Craig Venter marking the 10th anniversary of the human genome sequence warned of low standards in the translation of personal genomic information to consumers, including potentially 'deceptive marketing' [8]. It is a story as old as it is unfortunate, in which opportunistic individuals and companies may manipulate hype and hope for financial gain.

Though science is a fascinating endeavor for those of us in the laboratory, we should remember that public support of biomedical research typically relates to unmet clinical need. Investments in the HGP and hPSC research 
alike have been sold, in part, by articulating their potential to improve human health. Many benefits have already come to pass from this research and more are in store. Unfortunately, despite the best of efforts within laboratories and clinics, a great many people continue to suffer to the point of desperation. Societal expectations for the fruits of stem cell and personal genomics research are high but the general understanding of each, particularly their limitations, is low. This gap in public understanding is a particular concern, especially when it comes to the evaluation of personal medical risk or the drafting of new legislation to regulate science.

\section{Public engagement in translational research}

Potentially far-reaching projects, such as those of the ISSCR, are important for improving public understanding of stem cell research. Individual scientists willing and able to personally engage with the public and with policy makers also have a part to play [9]. Ultimately, people will make their own decisions but doing so from an informed position is the best possible situation. I urge scientists to be engaged. There is too much at stake to do otherwise.

That said, education alone is not the answer, especially when tensions emerge between scientists and the public, such as in the ideological debate around hESC research, or when an individual is motivated by a very personal desire to improve the life of a loved one. In a recent report from the American Academy of Arts and Sciences, entitled Do Scientists Understand the Public [10], researchers are warned against adopting a 'deficit model.' Such a view holds that 'disconnects' between scientists and lay people stem from public ignorance and that simply educating people will fix things. I am a big proponent of community education in the sciences but it is important to be open-minded when engaging people.

I think that we best serve the public by working to understand what people believe and their reasons for it before presenting our position. This is one difference between being an active participant and an authoritarian. Motivations are often personal and engagement is most effective when it is considerate of individual points of view, even if they are scientifically flawed. People sometimes do things despite having solid information to the contrary, especially if the only other option is to do nothing. This is part of the complexity of human existence in general and interactions with a medically needy but autonomously acting public in particular [11].

The American Academy of Arts and Sciences report also stresses the importance of anticipating problems before they arise [10]. Researchers need to be ahead of the curve in the interplay between science and society, including the shaping of policy. Failing to engage early puts scientists into a reactionary position from which it is difficult to promote change. Public involvement in translational stem cell and genomics research will only become more important, such as in studies where larger and more genetically diverse populations are beneficial, not to mention in future clinical trials.

My bottom line is this: combining stem cell and genome technologies is a terrific idea. I foresee a deeper understanding of human development and disease as a result of this union and, thus, a shorter path to improved therapies. An important corollary is that people are waiting for improvements in medical care and they are understandably impatient. This presents its own opportunities, not only to put new information on the table, but to partner with the public and policy makers in a way that ensures support. When such relationships also promote greater consumer protection against sham therapies, I fail to see a downside to engagement.

\section{Abbreviations}

hESC, human embryonic stem cell; HGP, Human Genome Project; hPSC, human pluripotent stem cell; iPSC, induced pluripotent stem cell; ISSCR, International Society for Stem Cell Research.

\section{Competing interests}

The author declares that he has no competing interests.

\section{Acknowledgements}

The author sincerely thanks Ms Andrea Fiorillo and Ms Anne Cherry, and Drs Asmin Tulpule, Hao Zhu and Katayoun Chamany. Space limitations force an abbreviated bibliography and the author apologizes for omitting relevant citations as a result. MWL is supported by a Howard Hughes Medical Institute Investigator Award to George Q Daley.

\section{Published: 6 July 2011}

\section{References}

1. Lander ES: Initial impact of the sequencing of the human genome. Nature 2011, 470:187-197.

2. Zhu H, Lensch MW, Cahan P, Daley GQ: Investigating monogenic and complex diseases with pluripotent stem cells. Nat Rev Genet 2011, 12:266-275.

3. Davies K: The $\$ 1,000$ Genome: the Revolution in DNA Sequencing and the New Era of Personalized Medicine. New York: Free Press; 2010.

4. Lau D, Ogbogu U, Taylor B, Stafinski T, Menon D, Caulfield T: Stem cell clinics online: the direct-to-consumer portrayal of stem cell medicine. Cell Stem Cell 2008, 3:591-594.

5. Hyun I, Lindvall O, Ahrlund-Richter L, Cattaneo E, Cavazzana-Calvo M, Cossu G, De Luca M, Fox IJ, Gerstle C, Goldstein RA, Hermerén G, High KA, Kim HO, Lee HP, Levy-Lahad E, Li L, Lo B, Marshak DR, McNab A, Munsie M, Nakauchi H, Rao M, Rooke HM, Valles CS, Srivastava A, Sugarman J, Taylor PL, Veiga A, Wong AL, Zoloth L, Daley GQ: New ISSCR guidelines underscore major principles for responsible translational stem cell research. Cell Stem Cell 2008, 3:607-609.

6. ISSCR: A closer look at stem cell treatments [http://wwW. closerlookatstemcells.org//AM/Template.cfm?Section=Home]

7. Pollack A: Walgreens Delays Selling Personal Genetic Test. The New York Times; 12 May, 2010.

8. Venter JC: Genome-sequencing anniversary. The human genome at 10: successes and challenges. Science 2011, 331:546-547.

9. Lensch MW: Science education as science advocacy: a personal view. In World Stem Cell Report 2010. Wellington, Florida: Genetics Policy Institute; 2010:34-37.

10. Mooney C: Do Scientists Understand the Public? Cambridge, Massachusetts: American Academy of Arts and Sciences; 2010.

11. Murdoch CE, Scott CT: Stem cell tourism and the power of hope. Am J Bioeth 2010, 10:16-23.

doi:10.1186/gm260

Cite this article as: Lensch MW: Public perception of stem cell and genomics research. Genome Medicine 2011, 3:44. 